\title{
A DISCRIMINAÇÃO DE PESSOAS VIVENDO COM HIV/AIDS NO TRABALHO: UMA ANÁLISE QUANTITATIVA E QUALITATIVA
}

\author{
Carla Rocha Pereira
}

Célia Landmann Szwarcwald

Giseli Nogueira Damacena

\begin{abstract}
Resumo
A discriminação de pessoas vivendo com HIV/aids está presente desde o começo da epidemia, interferindo negativamente na vida dessa população. Este trabalho analisa distintos aspectos relacionados à discriminação de soropositivos no Brasil no acesso e/ou ambiente de trabalho. Foi realizada uma análise quantitativa (pesquisa nacional) e qualitativa, entrevistas em profundidade (Assessoria Jurídica de ONG/aids) e grupo focal (Policlínica no município do Rio de Janeiro). Os resultados quantitativos indicaram que quanto mais baixa a escolaridade e renda do entrevistado, maior a percepção de discriminação. A pesquisa qualitativa relatou discriminação direta e indireta, sendo que aqueles com renda mais baixa possuíam emprego informal e não processaram seus perpetradores, distinguindo-se daqueles que procuraram a Assessoria Jurídica, que possuíam uma renda e escolaridade mais alta e que processaram seus empregadores. O estigma foi articulado com outros existentes na sociedade, sendo necessário programas de invenção para conscientizar a população sobre as diversas questões da epidemia.
\end{abstract}

Palavras-chave: HIV/AIDS. Discriminação. Trabalho. Brasil.

\section{DISCRIMINATION AGAINST PEOPLE LIVING WITH HIV/AIDS AT WORK: A QUANTITATIVE AND QUALITATIVE ANALYSIS}

\begin{abstract}
Discrimination against people living with HIV/AIDS has been present since the beginning of the epidemic, negatively interfering in the life of this population. This paper analyzes the different aspects related to the discrimination of seropositive people in Brazil in the access and/or work environment. A quantitative (national research) and qualitative analysis was performed, in-depth interviews (Legal Assistance of NGOs/AIDS) and focus group (Polyclinic in the city of Rio de Janeiro). The quantitative results indicated that the lower was the interviewee's education and income, greater was the perception of discrimination. The qualitative research reported direct and indirect discrimination, being that those with lower incomes had informal employment and did not sue their perpetrators, distinguishing themselves from those who sought legal advice, who had a higher income and education, and who sued their employers. The stigma was articulated with others existing in society, requiring programs of invention to make the population aware of the various issues of the epidemic.
\end{abstract}

Keywords: HIV/AIDS. Discrimination. Work. Brazil.

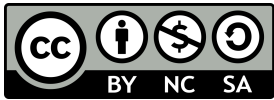




\section{INTRODUÇÃO}

A epidemia de aids surgiu no começo da década de 1980, nos Estados Unidos e na África (FORATTINI, 1993), como uma doença que matava os indivíduos infectados, rapidamente. $\mathrm{Na}$ mesma década, foi descoberto o vírus causador da doença, o HIV, transmitido através das relações sexuais e do sangue contaminado (incluindo o compartilhamento de seringas e transfusão de sangue).

Os indivíduos infectados pelo HIV estavam vinculados a alguns subgrupos populacionais específicos e a aids foi relacionada àqueles de maior vulnerabilidade. Na mesma época, iniciou-se o uso de termos depreciativos, como "câncer gay" e GRID (Gay-Related Immune Deficiency), principalmente pelo grande número de jovens homossexuais infectados com o vírus na primeira década da epidemia (BASTOS, 2006). No Brasil, o HIV surgiu nas grandes capitais, como Rio de Janeiro e São Paulo, e entre alguns grupos, como os homossexuais, bissexuais e aqueles que precisavam de hemoderivados, como os hemofílicos (SZWARCWALD; BASTOS; CASTILHO, 1998; BASTOS, 2006; SOUZA-JÚNIOR, 2009).

Segundo dados epidemiológicos brasileiros, foram totalizados 982.129 casos de aids no período de 1980 até junho de 2018 no país, com uma diminuição na taxa de detecção de entre os anos de 2012 a 2017, produzindo um decréscimo de 15,7\% (BRASIL, 2018). Contudo, a transmissão do vírus entre os jovens homossexuais vem crescendo no país, necessitando de medidas e programas específicos de conscientização que abordem as formas de transmissão e proteção contra o HIV para esse grupo (GROTZ; PARKER, 2015).

Apesar dos grandes avanços no que tange ao tratamento, questões de cunho social continuam a assolar as pessoas vivendo com HIV/aids (PVHA) e termos depreciativos ainda são utilizados, renovando os preconceitos (BASTOS, 2013). Historicamente, o estigma de HIV/aids decorre da associação entre as vias de transmissão do vírus (sexual e sanguínea), os grupos sociais atingidos pelo HIV e as normas sociais existentes antes da epidemia de aids, relacionadas aos estereótipos de gênero e à normatização da sexualidade.

Pode-se dizer que a moralidade se insere na concepção do estigma, pois o portador do HIV adquire uma marca depreciativa (GOFFMAN, 2013). A partir da ideia de que certa pessoa não deveria estar inserida na sociedade, ocorre a ação discriminatória, que pode ser realizada por meio da tentativa de excluir o indivíduo do convívio social (PARKER, 2013). Diversos artigos correlacionam a influência do estigma e da discriminação na piora da qualidade de vida das PVHA no que tange ao trabalho e recorrente é o medo da descoberta do diagnóstico pelo 
empregador, podendo acarretar na demissão desses indivíduos, além de interferir na aderência ao tratamento (BEZABHE et al., 2014).

O presente artigo tem por objetivo analisar os aspectos da discriminação de PVHA no acesso e/ou ambiente de trabalho no Brasil através de dados quantitativos e qualitativos. Pretende-se entender como ocorre a discriminação no emprego, seja formal e informal, além dos reflexos da infeção do HIV na vida laborativa dessa população.

\section{MÉTODO}

Para a apreensão da discriminação de PVHA no trabalho, foi empregada diversas metodologias de pesquisa. Na etapa quantitativa, utilizou-se dados coletados na pesquisa "Pacientes em Terapia Antirretroviral no Brasil: Resposta do Sistema de Saúde e Qualidade de Vida", desenvolvida por uma demanda do Ministério da Saúde e coordenada pela Fundação Oswaldo Cruz em 2008. Ela teve por objetivo avaliar a qualidade de vida e o desempenho do sistema de saúde a partir da perspectiva dos usuários, pacientes em terapia antirretroviral (TARV) no Brasil ${ }^{1}$.

Para a coleta das informações, foi utilizado um questionário modular que abordou os seguintes temas: características sociodemográficas e referentes ao domicílio do paciente; características clínicas relacionadas ao tratamento; autoavaliação do estado de saúde; resposta do sistema de saúde; percepção da qualidade de vida; e perdas e benefícios relacionados à doença. O questionário foi aplicado por entrevistadores previamente treinados em Unidades de Dispensa de Medicamentos (UDM) no Brasil (SOUZA-JÚNIOR; SZWARCWALD; CASTILHO, 2011). Foi realizada uma análise descritiva para avaliar o perfil das pessoas em TARV, segundo três vertentes: características sociodemográficas, estado de saúde e questões relacionadas diretamente à infecção por HIV/aids. As análises foram realizadas por sexo e foram calculados os intervalos de confiança com nível de significância de $95 \%$.

Para caracterizar a situação sociodemográfica, foram utilizadas as seguintes variáveis: faixa etária; grau de escolaridade; estado civil; raça/cor da pele; trabalha atualmente; situação atual de trabalho; e renda. Para a caracterização do estado de saúde, foram consideradas as

\footnotetext{
${ }^{1} \mathrm{O}$ tamanho de amostra foi calculado para estimar a proporção de pacientes em TARV que avaliam sua qualidade de vida como moderada ou boa. Em estudo realizado na Austrália (PITTS; GRIERSON; MISSON, 2005), 35\% das pessoas vivendo com HIV/aids com menos de 50 anos relataram condições adversas de saúde. Tomando esta estimativa como base para o cálculo do tamanho da amostra e considerando um intervalo de $95 \%$ de confiança, com erro bilateral de 3\%, foram obtidos 971 pacientes. Tendo em vista que a amostragem foi por conglomerados, em dois estágios de seleção, considerou-se um efeito de desenho de 1,3 e obteve-se o tamanho de amostra de 1260 pacientes.
} 
seguintes questões: autoavaliação de saúde; autoavaliação da capacidade de trabalho; autoavaliação da aparência física; grau de dificuldade em realizar atividades de rotina; e grau de dificuldade em seguir o tratamento. E, para descrever as questões relacionadas diretamente à infecção por HIV/aids, foram consideradas as seguintes situações: piora na situação financeira; mudança de local de moradia; perda de independência; perda de emprego; e benefícios do governo. As análises foram realizadas utilizando o aplicativo estatístico Statistical for Package for the Social Science (SPSS), versão 21.0, que leva em consideração o efeito do plano amostral.

A partir da análise prévia dos dados quantitativos, que apontou a perda de emprego, a piora da situação financeira e a mudança de local de moradia como problemas relacionados à infecção pelo HIV/aids, foi elaborado o referencial metodológico para a coleta dos dados qualitativos, que utilizou grupo focal e entrevistas semiestruturadas (2015 e 2016). O primeiro passo na escuta das PVHA foi a realização do grupo focal em uma policlínica da cidade do Rio de Janeiro, entre aqueles que acessavam o setor de infectologia. A escolha deste local se deu pelo fato de o setor de infectologia atender um grande número de PVHA, além de realizar grupos de convivência que debatiam diversos temas relacionados a viver com HIV/aids. Neste local, foram elegíveis os usuários que sofreram algum tipo de discriminação no emprego (formal ou informal) e que não processaram os seus perpetradores, totalizando seis pessoas. Este método de pesquisa tem por princípio a realização de entrevistas ou conversas em grupos pequenos, que tenham de seis a doze pessoas e que durem, no máximo, até uma hora e meia (MINAYO, 2014).

Diferentemente da policlínica, foram realizadas entrevistas semiestruturadas com pessoas que passaram por situação de discriminação no trabalho em uma organização não governamental (ONG) do Estado do Rio de Janeiro e que fornecia serviço de Assessoria Jurídica para as PVHA. Foram utilizadas as mesmas perguntas do grupo focal para que as respostas pudessem ser comparadas. Foram elegíveis as PVHA que buscaram a Assessoria Jurídica da ONG ou que fizeram alguma atividade ofertada por essa instituição, além de terem entrado com processos de discriminação relacionados ao trabalho. Dessa forma, dois homens e uma mulher foram entrevistados. Também houve observação participante ${ }^{2}$ em grupos de convivência realizados na sala de espera da infectologia da policlínica e em eventos/cursos organizados pela ONG.

\footnotetext{
2 Técnica utilizada pelo antropólogo Malinowski, desenvolvida no seu trabalho de campo entre os nativos das Ilhas Trobiand e descrita no clássico livro “Os Argonautas do Pacífico Ocidental”, publicado em 1922 (MINAYO, 2014).
} 


\section{RESULTADOS}

\subsection{OS DADOS QUANTITATIVOS}

No que tange aos dados quantitativos, foram entrevistados 1.245 pacientes em TARV. Destes, $58,5 \%$ eram do sexo masculino e $41,5 \%$ do sexo feminino. A maioria dos pacientes entrevistados tinham entre 40 e 59 anos, tanto entre homens $(78,6 \%)$ quanto mulheres $(73,9 \%)$. Os menores percentuais relacionados à idade dos respondentes foram observados entre os jovens de 18 a 24 anos. Resultados por grau de escolaridade mostraram que $44 \%$ dos pacientes pesquisados não possuíam instrução ou tinham apenas o ensino fundamental incompleto. Os menores percentuais foram observados entre os mais escolarizados, com superior completo ou mais; $10 \%$ entre os homens e $5 \%$ entre as mulheres (Tabela 1).

Tabela 1. Distribuição percentual dos pacientes em terapia antirretroviral por sexo segundo características sociodemográficas. Brasil, $2008(\mathrm{n}=1.245)$

\begin{tabular}{|c|c|c|c|c|c|c|c|c|c|c|}
\hline \multirow{3}{*}{\multicolumn{2}{|c|}{ Características sociodemográficas }} & \multicolumn{3}{|c|}{ Masculino } & \multicolumn{3}{|c|}{ Feminino } & \multicolumn{3}{|c|}{ Total } \\
\hline & & \multirow{2}{*}{$\%$} & \multicolumn{2}{|c|}{ IC $95 \%$} & \multirow{2}{*}{$\%$} & \multicolumn{2}{|c|}{ IC $95 \%$} & \multirow{2}{*}{$\%$} & \multicolumn{2}{|c|}{ IC $95 \%$} \\
\hline & & & LI & $\mathbf{L S}$ & & LI & $\mathbf{L S}$ & & LI & LS \\
\hline \multicolumn{2}{|l|}{ Total } & 58,5 & 54,5 & 62,5 & 41,5 & 37,5 & 45,5 & - & - & - \\
\hline \multirow{4}{*}{ Faixa de idade } & 18 a 24 anos & 3,2 & 2,0 & 4,9 & 5,3 & 3,1 & 8,9 & 4,1 & 2,8 & 5,9 \\
\hline & 25 a 39 anos & 10,0 & 7,1 & 14,1 & 14,2 & 10,0 & 19,9 & 11,8 & 9,0 & 15,4 \\
\hline & 40 a 59 anos & 78,6 & 74,5 & 82,1 & 73,9 & 68,4 & 78,8 & 76,6 & 73,1 & 79,8 \\
\hline & 60 anos ou mais & 8,2 & 6,1 & 10,9 & 6,5 & 4,1 & 10,3 & 7,5 & 5,8 & 9,7 \\
\hline \multirow{4}{*}{$\begin{array}{l}\text { Grau de } \\
\text { escolaridade }\end{array}$} & $\begin{array}{l}\text { Sem instrução e fundamental } \\
\text { incompleto }\end{array}$ & 39,7 & 34,6 & 45,1 & 50,1 & 43,9 & 56,3 & 44,0 & 39,2 & 49,0 \\
\hline & $\begin{array}{l}\text { Fundamental completo e médio } \\
\text { incompleto }\end{array}$ & 20,0 & 16,9 & 23,4 & 20,2 & 16,7 & 24,3 & 20,1 & 17,6 & 22,8 \\
\hline & $\begin{array}{l}\text { Médio completo e superior } \\
\text { incompleto }\end{array}$ & 30,3 & 25,8 & 35,2 & 24,7 & 20,2 & 29,8 & 28,0 & 24,5 & 31,7 \\
\hline & Superior completo ou mais & 10,0 & 7,3 & 13,6 & 5,0 & 3,2 & 7,9 & 8,0 & 6,0 & 10,5 \\
\hline \multirow{4}{*}{ Estado civil } & Solteiro(a) & 44,7 & 39,6 & 49,8 & 18,6 & 15,1 & 22,7 & 33,9 & 30,3 & 37,7 \\
\hline & $\begin{array}{l}\text { Casado(a) / Vive com } \\
\text { companheiro(a) }\end{array}$ & 34,7 & 30,6 & 38,9 & 40,0 & 34,9 & 45,3 & 36,9 & 33,2 & 40,7 \\
\hline & Separado(a) / Divorciado(a) & 16,8 & 13,8 & 20,4 & 24,1 & 20,0 & 28,7 & 19,8 & 17,1 & 22,9 \\
\hline & Viúvo(a) & 3,8 & 2,5 & 5,8 & 17,3 & 13,7 & 21,6 & 9,4 & 7,7 & 11,4 \\
\hline \multirow{5}{*}{ Raça / cor da pele } & Branca & 47,8 & 40,8 & 54,9 & 42,5 & 34,9 & 50,5 & 45,6 & 39,3 & 52,1 \\
\hline & Preta & 11,9 & 9,3 & 15,1 & 16,1 & 13,0 & 19,8 & 13,7 & 11,5 & 16,2 \\
\hline & Parda & 38,5 & 32,7 & 44,7 & 38,6 & 31,9 & 45,8 & 38,6 & 33,3 & 44,4 \\
\hline & Outras & 1,8 & 0,9 & 3,4 & 2,7 & 1,5 & 5,0 & 2,2 & 1,3 & 3,6 \\
\hline & Sim & 44,9 & 10,2 & 49,8 & 38,1 & 33,1 & 43,3 & 42,1 & 38,1 & 46,2 \\
\hline
\end{tabular}




\begin{tabular}{l|l|ccc|ccc|ccc}
$\begin{array}{l}\text { Trabalha } \\
\text { atualmente }\end{array}$ & Não & 55,1 & 50,2 & 59,8 & 61,9 & 56,7 & 66,9 & 57,9 & 53,8 & 61,9 \\
\hline \multirow{5}{*}{ Renda atual } & Não tem rendimento & 13,6 & 11,1 & 16,5 & 24,1 & 20,3 & 28,3 & 17,9 & 15,4 & 20,7 \\
& $\mathrm{R} \$ 1,00$ a $\mathrm{R} \$ 379,00$ & 6,2 & 4,3 & 8,7 & 11,8 & 8,8 & 15,7 & 8,5 & 6,6 & 11,0 \\
& $\mathrm{R} \$ 380,00$ a $\mathrm{R} \$ 759,00$ & 38,1 & 33,4 & 43,0 & 46,8 & 41,8 & 51,9 & 41,7 & 37,9 & 45,6 \\
& $\mathrm{R} \$ 760,00$ a $\mathrm{R} \$ 1.139,00$ & 16,4 & 13,4 & 19,9 & 8,7 & 6,4 & 11,9 & 13,3 & 10,9 & 16,0 \\
& $\mathrm{R} \$ 1.140,00$ a $\mathrm{R} \$ 1.999,00$ & 15,6 & 12,6 & 19,1 & 4,9 & 3,2 & 7,4 & 11,2 & 9,0 & 13,8 \\
& $\mathrm{R} \$ 2.000,00$ a $\mathrm{R} \$ 4.999,00$ & 8,2 & 6,1 & 11,0 & 2,3 & 1,2 & 4,3 & 5,8 & 4,3 & 7,7 \\
& $\mathrm{R} \$ 5.000$ ou mais & 1,0 & 0,5 & 1,9 & 0,0 & - & - & 0,6 & 0,3 & 1,1 \\
& Não sabe / Não informou & 1,0 & 0,4 & 2,2 & 1,4 & 0,7 & 2,7 & 1,1 & 0,6 & 2,1 \\
\hline
\end{tabular}

Fonte: Autoria própria

Entre os homens em TARV, a maioria se declarou solteiro $(44,7 \%)$ e com a cor da pele branca $(47,8 \%)$. Entre as mulheres, a maioria também se declarou com a pele branca $(42,5 \%)$, porém, em relação ao estado civil, grande parte era casada ou vivia com companheiro (a) (40\%). O percentual de solteiras foi de apenas 18,6\%. Quase $60 \%$ dos entrevistados não estavam trabalhando no momento da pesquisa. Cerca de $18 \%$ dos entrevistados declararam não ter nenhum rendimento (Tabela 1).

Sobre as questões relacionadas ao estado de saúde, 91,6\% autoavaliaram a saúde como excelente, boa ou moderada; este percentual se manteve próximo tanto para homens como para mulheres. Já em relação à autoavaliação de saúde ruim ou péssima, as mulheres tiveram maiores percentuais que os homens, 10,1 e 7,1\%, respectivamente. Em relação à capacidade de trabalho, quase $75 \%$ dos entrevistados disseram ter capacidade excelente, boa ou moderada para o trabalho. Logo, um quarto dos entrevistados disseram estar com uma capacidade ruim ou péssima para trabalhar. Sobre a autoavaliação da aparência física, 13\% dos homes e 18,6\% das mulheres mencionaram estar com uma aparência ruim ou péssima. 13,5\% dos entrevistados disseram ter grau intenso ou muito intenso de dificuldade em realizar atividades de rotina, sendo o percentual entre os homens de $11,5 \%$ e $16,3 \%$ entre as mulheres. 92,5\% relataram nenhum, leve ou grau moderado de dificuldade para seguir o tratamento (Tabela 2). 
Tabela 2. Distribuição percentual dos pacientes em terapia antirretroviral por sexo segundo questões relacionadas ao estado de saúde e relacionadas diretamente à infecção por HIV/aids. Brasil, 2008 (n=1.245)

\begin{tabular}{|c|c|c|c|c|c|c|c|c|c|c|}
\hline \multirow{3}{*}{\multicolumn{2}{|c|}{$\begin{array}{l}\text { Questões relacionadas diretamente à infecção por } \\
\text { HIV/aids }\end{array}$}} & \multicolumn{3}{|c|}{ Masculino } & \multicolumn{3}{|c|}{ Feminino } & \multicolumn{3}{|c|}{ Total } \\
\hline & & \multirow{2}{*}{$\%$} & \multicolumn{2}{|c|}{ IC $95 \%$} & \multirow{2}{*}{$\%$} & \multicolumn{2}{|c|}{ IC $95 \%$} & \multirow{2}{*}{$\%$} & \multicolumn{2}{|c|}{ IC $95 \%$} \\
\hline & & & LI & $\mathbf{L S}$ & & LI & $\mathbf{L S}$ & & LI & LS \\
\hline \multicolumn{2}{|l|}{ Total } & 58,5 & 54,5 & 62,5 & 41,5 & 37,5 & 45,5 & - & - & - \\
\hline \multirow{2}{*}{$\begin{array}{l}\text { Autoavaliação de } \\
\text { saúde }\end{array}$} & Excelente / Boa / Moderada & 92,9 & 90,3 & 94,8 & 89,9 & 85,0 & 93,3 & 91,6 & 89,4 & 93,5 \\
\hline & Ruim / Péssima & 7,1 & 5,2 & 9,7 & 10,1 & 6,7 & 15,0 & 8,4 & 6,5 & 10,6 \\
\hline \multirow{2}{*}{$\begin{array}{l}\text { Autoavaliação da } \\
\text { capacidade de } \\
\text { trabalho }\end{array}$} & Excelente / Boa / Moderada & 72,7 & 68,9 & 76,3 & 77,9 & 72,5 & 82,5 & 74,9 & 71,4 & 78,0 \\
\hline & Ruim / Péssima & 27,3 & 23,7 & 31,1 & 22,1 & 17,5 & 27,5 & 25,1 & 22,0 & 28,6 \\
\hline \multirow{2}{*}{$\begin{array}{l}\text { Autoavaliação da } \\
\text { aparência física }\end{array}$} & Excelente / Boa / Moderada & 87,0 & 83,7 & 89,7 & 81,4 & 76,9 & 85,1 & 84,7 & 81,6 & 87,3 \\
\hline & Ruim / Péssima & 13,0 & 10,3 & 16,3 & 18,6 & 14,9 & 23,1 & 15,3 & 12,7 & 18,4 \\
\hline \multirow{2}{*}{$\begin{array}{l}\text { Grau de } \\
\text { dificuldade em } \\
\text { realizar atividades } \\
\text { de rotina }\end{array}$} & Nenhum / Leve / Moderado & 88,5 & 85,5 & 90,9 & 83,7 & 78,8 & 87,6 & 86,5 & 83,6 & 89,0 \\
\hline & Intenso / Muito intenso & 11,5 & 9,1 & 14,5 & 16,3 & 12,4 & 21,2 & 13,5 & 11,0 & 16,4 \\
\hline \multirow{2}{*}{$\begin{array}{l}\text { Grau de } \\
\text { dificuldade em } \\
\text { seguir o } \\
\text { tratamento }\end{array}$} & Nenhum / Leve / Moderado & 93,8 & 91,2 & 95,7 & 90,7 & 87,7 & 93,0 & 92,5 & 90,7 & 94,0 \\
\hline & Intenso / Muito intenso & 6,2 & 4,3 & 8,8 & 9,3 & 7,0 & 12,3 & 7,5 & 6,0 & 9,3 \\
\hline \multirow{2}{*}{$\begin{array}{l}\text { Piora na situação } \\
\text { financeira }\end{array}$} & Sim & 37,3 & 31,7 & 43,2 & 35,6 & 29,6 & 42,0 & 36,6 & 31,8 & 41,6 \\
\hline & Não & 62,7 & 56,8 & 68,3 & 64,4 & 58,0 & 70,4 & 63,4 & 58,4 & 68,2 \\
\hline \multirow{2}{*}{$\begin{array}{l}\text { Mudança de local } \\
\text { de moradia }\end{array}$} & Sim & 15,2 & 11,9 & 19,2 & 13,8 & 10,0 & 18,7 & 14,6 & 11,7 & 18,1 \\
\hline & Não & 84,8 & 80,8 & 88,1 & 86,2 & 81,3 & 90,0 & 85,4 & 81,9 & 88,3 \\
\hline \multirow{2}{*}{$\begin{array}{l}\text { Perda de } \\
\text { independência }\end{array}$} & Sim & 14,2 & 10,5 & 19,1 & 16,5 & 11,7 & 22,9 & 15,2 & 11,4 & 19,9 \\
\hline & Não & 85,8 & 80,9 & 89,5 & 83,5 & 77,1 & 88,3 & 84,8 & 80,1 & 88,6 \\
\hline \multirow{2}{*}{ Perda de emprego } & Sim & 19,3 & 16,0 & 23,1 & 22,8 & 19,0 & 27,1 & 20,7 & 18,2 & 23,5 \\
\hline & Não & 80,7 & 76,9 & 84,0 & 77,2 & 72,9 & 81,0 & 79,3 & 76,5 & 81,8 \\
\hline \multirow{6}{*}{$\begin{array}{l}\text { Benefícios do } \\
\text { governo }\end{array}$} & Auxílio-Doença & 30,5 & 26,0 & 35,5 & 21,4 & 17,4 & 26,0 & 26,8 & 23,0 & 30,9 \\
\hline & Aposentadoria por invalidez & 16,7 & 13,5 & 20,6 & 8,2 & 6,0 & 11,0 & 13,2 & 10,9 & 15,9 \\
\hline & $\begin{array}{l}\text { Amparo Assistencial ao Portador de } \\
\text { Deficiência (LOAS) }\end{array}$ & 2,7 & 1,6 & 4,7 & 2,5 & 1,4 & 4,5 & 2,7 & 1,6 & 4,3 \\
\hline & $\begin{array}{l}\text { Passe livre para transporte (isenção } \\
\text { tarifária) }\end{array}$ & 31,1 & 23,8 & 39,5 & 34,4 & 25,5 & 44,6 & 32,5 & 24,8 & 41,2 \\
\hline & Nenhum & 38,5 & 33,4 & 43,9 & 49,8 & 42,8 & 56,8 & 43,2 & 37,8 & 48,7 \\
\hline & Outros & 6,6 & 4,8 & 9,0 & 3,9 & 2,3 & 6,4 & 5,5 & 4,0 & 7,4 \\
\hline
\end{tabular}

Fonte: Autoria própria

Quanto aos problemas que aconteceram aos entrevistados, relacionados à infecção por HIV/aids, 36,6\% tiveram piora na situação financeira, 14,6\% tiveram mudança de local de moradia, 15,2\% relataram perda de independência e 20,7\%, perda de emprego. Em relação a diferenças por sexo, os homens tiveram maiores percentuais de piora na situação financeira e tiveram que mudar mais do local de moradia que as mulheres. Já as mulheres, perderam mais sua independência e mais emprego do que os homens (Tabela 2). 
Em se tratando do acesso aos benefícios do governo, 26,8\% estavam afastados do trabalho em função do auxílio doença e 32,5\% conseguiram o passe livre para o transporte público. Contudo, 43,2\% dos entrevistados não conseguiram nenhum benefício, sobretudo as mulheres, 49,8\% (Tabela 2).

$\mathrm{Na}$ análise por perda de emprego no momento da pesquisa, entre os homens da faixa etária de 18 a 24 anos, 20\% ficaram desempregados devido à infecção por HIV/aids e 27,1\% das mulheres de 25 a 39 anos, também. Em relação aos homens sem instrução ou com ensino fundamental incompleto, $21,4 \%$ perderam o emprego e, entre as mulheres, o percentual foi de $27,6 \%$. Dentre os homens que autoavaliaram sua saúde como ruim ou péssima, 36,5\% perderam o emprego e 39,2\% das mulheres que fizeram essa avaliação também perderam o emprego. No que tange à capacidade de trabalho excelente, boa ou moderada, a perda de emprego foi de $18 \%$ entre homens e $21 \%$ entre as mulheres. Sobre o grau de dificuldade em seguir o tratamento, dos homens que relataram não ter nenhum grau de dificuldade, ou um grau leve ou moderado, $18 \%$ perderam o emprego. Nas mulheres, o percentual foi de 22,5\% (Tabela 3 ).

Tabela 3. Distribuição percentual dos pacientes em terapia antirretroviral por perda de emprego devido à infecção por HIV/aids e sexo, segundo variáveis de estudo. Brasil, $2008(n=1.245)$

\begin{tabular}{|c|c|c|c|c|c|c|c|c|c|c|c|c|c|}
\hline \multirow{4}{*}{\multicolumn{2}{|c|}{ Variáveis de estudo }} & \multicolumn{6}{|c|}{ Masculino } & \multicolumn{6}{|c|}{ Feminino } \\
\hline & & \multirow{2}{*}{\multicolumn{3}{|c|}{$\begin{array}{r}\begin{array}{c}\text { Não perdeu o } \\
\text { emprego }\end{array} \\
\text { IC } 95 \%\end{array}$}} & \multicolumn{3}{|c|}{ Perdeu o emprego } & \multicolumn{3}{|c|}{$\begin{array}{l}\text { Não perdeu o } \\
\text { emprego }\end{array}$} & \multicolumn{3}{|c|}{ Perdeu o emprego } \\
\hline & & & & & \multirow{2}{*}{$\%$} & \multicolumn{2}{|c|}{ IC $95 \%$} & \multirow{2}{*}{$\%$} & \multicolumn{2}{|c|}{ IC $95 \%$} & \multirow{2}{*}{$\%$} & \multicolumn{2}{|c|}{ IC $95 \%$} \\
\hline & & $\%$ & $\mathbf{L I}$ & LS & & $\mathbf{L I}$ & $\mathbf{L S}$ & & LI & LS & & $\mathbf{L I}$ & $\mathbf{L S}$ \\
\hline \multicolumn{2}{|l|}{ Total } & 80,7 & 76,9 & 84,0 & 19,3 & 16,0 & 23,1 & 77,2 & 72,9 & 81,0 & 22,8 & 19,0 & 27,1 \\
\hline \multirow{4}{*}{$\begin{array}{l}\text { Faixa de } \\
\text { idade }\end{array}$} & 18 a 24 anos & 80,0 & 51,7 & 93,7 & 20,0 & 6,3 & 48,3 & 83,3 & 59,6 & 94,4 & 16,7 & 5,6 & 40,4 \\
\hline & 25 a 39 anos & 81,3 & 68,3 & 89,7 & 18,8 & 10,3 & 31,7 & 72,9 & 61,8 & 81,8 & 27,1 & 18,2 & 38,2 \\
\hline & 40 a 59 anos & 80,2 & 75,3 & 84,3 & 19,8 & 15,7 & 24,7 & 75,9 & 68,6 & 81,9 & 24,1 & 18,1 & 31,4 \\
\hline & 60 anos ou mais & 97,4 & 84,0 & 99,6 & 2,6 & 0,4 & 16,0 & 86,4 & 65,4 & 95,5 & 13,6 & 4,5 & 34,6 \\
\hline \multirow{4}{*}{$\begin{array}{l}\text { Grau de } \\
\text { escolaridade }\end{array}$} & $\begin{array}{l}\text { Sem instrução e } \\
\text { fundamental } \\
\text { incompleto }\end{array}$ & 78,6 & 72,0 & 84,0 & 21,4 & 16,0 & 28,0 & 72,4 & 66,3 & 77,7 & 27,6 & 22,3 & 33,7 \\
\hline & $\begin{array}{l}\text { Fundamental } \\
\text { completo e } \\
\text { médio } \\
\text { incompleto }\end{array}$ & 79,5 & 72,5 & 85,0 & 20,5 & 15,0 & 27,5 & 76,0 & 64,6 & 84,6 & 24,0 & 15,4 & 35,4 \\
\hline & $\begin{array}{l}\text { Médio completo } \\
\text { e superior } \\
\text { incompleto }\end{array}$ & 83,3 & 76,5 & 88,4 & 16,7 & 11,6 & 23,5 & 87,4 & 81,1 & 91,8 & 12,6 & 8,2 & 18,9 \\
\hline & $\begin{array}{l}\text { Superior } \\
\text { completo ou } \\
\text { mais }\end{array}$ & 83,6 & 71,6 & 91,1 & 16,4 & 8,9 & 28,4 & 80,8 & 62,3 & 91,4 & 19,2 & 8,6 & 37,7 \\
\hline \multirow{2}{*}{$\begin{array}{l}\text { Autoavaliação } \\
\text { de saúde }\end{array}$} & $\begin{array}{l}\text { Excelente / Boa } \\
\text { / Moderada }\end{array}$ & 82,0 & 78,4 & 85,1 & 18,0 & 14,9 & 21,6 & 79,0 & 74,6 & 82,9 & 21,0 & 17,1 & 25,4 \\
\hline & Ruim / Péssima & 63,5 & 49,0 & 75,8 & 36,5 & 24,2 & 51,0 & 60,8 & 48,0 & 72,2 & 39,2 & 27,8 & 52,0 \\
\hline
\end{tabular}




\begin{tabular}{|c|c|c|c|c|c|c|c|c|c|c|c|c|c|}
\hline \multirow{2}{*}{$\begin{array}{l}\text { Autoavaliação } \\
\text { da capacidade } \\
\text { de trabalho }\end{array}$} & $\begin{array}{l}\text { Excelente / Boa } \\
\text { / Moderada }\end{array}$ & 82,3 & 78,3 & 85,7 & 17,7 & 14,3 & 21,7 & 81,3 & 76,3 & 85,4 & 18,7 & 14,6 & 23,7 \\
\hline & Ruim / Péssima & 76,4 & 69,1 & 82,4 & 23,6 & 17,6 & 30,9 & 62,8 & 53,5 & 71,3 & 37,2 & 28,7 & 46,5 \\
\hline \multirow{2}{*}{$\begin{array}{l}\text { Grau de } \\
\text { dificuldade } \\
\text { em seguir o } \\
\text { tratamento }\end{array}$} & $\begin{array}{l}\text { Nenhum / Leve } \\
\text { / Moderado }\end{array}$ & 81,9 & 78,2 & 85,1 & 18,1 & 14,9 & 21,8 & 77,5 & 72,4 & 81,8 & 22,5 & 18,2 & 27,6 \\
\hline & $\begin{array}{l}\text { Intenso / Muito } \\
\text { intenso }\end{array}$ & 62,2 & 46,5 & 75,8 & 37,8 & 24,2 & 53,5 & 75,0 & 60,5 & 85,5 & 25,0 & 14,5 & 39,5 \\
\hline \multirow{6}{*}{$\begin{array}{l}\text { Benefícios do } \\
\text { governo }\end{array}$} & Auxílio-Doença & 74,0 & 66,2 & 80,5 & 26,0 & 19,5 & 33,8 & 66,4 & 59,4 & 72,7 & 33,6 & 27,3 & 40,6 \\
\hline & $\begin{array}{l}\text { Aposentadoria } \\
\text { por invalidez }\end{array}$ & 73,8 & 65,6 & 80,6 & 26,2 & 19,4 & 34,4 & 64,3 & 49,2 & 77,0 & 35,7 & 23,0 & 50,8 \\
\hline & $\begin{array}{l}\text { Amparo } \\
\text { Assistencial ao } \\
\text { Portador de } \\
\text { Deficiência } \\
\text { (LOAS) }\end{array}$ & 65,0 & 41,0 & 83,2 & 35,0 & 16,8 & 59,0 & 61,5 & 34,0 & 83,2 & 38,5 & 16,8 & 66,0 \\
\hline & $\begin{array}{l}\text { Passe livre para } \\
\text { transporte } \\
\text { (isenção } \\
\text { tarifária) }\end{array}$ & 74,0 & 68,2 & 79,1 & 26,0 & 20,9 & 31,8 & 76,3 & 70,1 & 81,5 & 23,7 & 18,5 & 29,9 \\
\hline & Nenhum & 87,2 & 82,6 & 90,7 & 12,8 & 9,3 & 17,4 & 80,9 & 74,2 & 86,1 & 19,1 & 13,9 & 25,8 \\
\hline & Outros & 87,5 & 72,5 & 94,9 & 12,5 & 5,1 & 27,5 & 65,0 & 44,6 & 81,1 & 35,0 & 18,9 & 55,4 \\
\hline \multirow{2}{*}{$\begin{array}{l}\text { Piora na } \\
\text { situação } \\
\text { financeira }\end{array}$} & Sim & 59,6 & 52,8 & 66,0 & 40,4 & 34,0 & 47,2 & 52,5 & 45,5 & 59,3 & 47,5 & 40,7 & 54,5 \\
\hline & Não & 93,2 & 90,3 & 95,3 & 6,8 & 4,7 & 9,7 & 90,9 & 87,4 & 93,5 & 9,1 & 6,5 & 12,6 \\
\hline \multirow{2}{*}{$\begin{array}{l}\text { Mudança de } \\
\text { local de } \\
\text { moradia }\end{array}$} & Sim & 50,5 & 40,7 & 60,2 & 49,5 & 39,8 & 59,3 & 49,3 & 39,1 & 59,5 & 50,7 & 40,5 & 60,9 \\
\hline & Não & 86,1 & 82,5 & 89,0 & 13,9 & 11,0 & 17,5 & 81,7 & 77,6 & 85,2 & 18,3 & 14,8 & 22,4 \\
\hline \multirow{2}{*}{$\begin{array}{l}\text { Perda de } \\
\text { independência }\end{array}$} & Sim & 66,3 & 56,3 & 75,1 & 33,7 & 24,9 & 43,7 & 64,7 & 53,1 & 74,8 & 35,3 & 25,2 & 46,9 \\
\hline & Não & 83,1 & 79,4 & 86,2 & 16,9 & 13,8 & 20,6 & 79,7 & 74,9 & 83,8 & 20,3 & 16,2 & 25,1 \\
\hline \multirow{2}{*}{$\begin{array}{l}\text { Trabalha } \\
\text { atualmente }\end{array}$} & Sim & 47,7 & 42,0 & 53,5 & 33,3 & 25,5 & 42,2 & 40,8 & 35,2 & 46,7 & 29,1 & 21,9 & 37,4 \\
\hline & Não & 52,3 & 46,5 & 58,0 & 66,7 & 57,8 & 74,5 & 52,9 & 53,3 & 64,8 & 70,5 & 62,6 & 78,1 \\
\hline
\end{tabular}

Fonte: Autoria própria

Das pessoas que declararam ter o Amparo Assistencial ao Portador de Deficiências (LOAS), 35\% perderam o emprego dentre os homens e 38,5 dentre as mulheres. Sobre a piora na situação financeira, 40,4\% dos homens perderam o emprego e 47,5 das mulheres também. Os percentuais são ainda maiores para os que relataram ter que mudar o local de moradia por conta da infecção por HIV/aids, 49,5\% dos homens perderam o emprego e 50,7\% das mulheres também. Dos homens que perderam sua independência, 33,7\% por conta da perda de emprego e entre as mulheres 35,3\%. Ressaltamos que 70,5\% dos entrevistados que não estavam trabalhando no momento da entrevista perderam o emprego em função da infecção por HIV, principalmente os homens $(66,7 \%)$ (Tabela 3). 


\subsection{OS DADOS QUALITATIVOS}

A discriminação no trabalho entre os entrevistados vivendo com HIV/aids foi percebida de forma distinta. Entre os usuários do serviço de saúde, houve casos de discriminação direta e a demissão ou o afastamento do trabalho ocorreram claramente em função de HIV/aids. Já em outras situações, a discriminação ocorreu de forma sutil, indireta, e sendo entendida após determinadas ações ou gestos dos empregadores:

[...] no restaurante da Pavuna eu fui notando que eles, tipo assim, depois, acabava o meu horário de trabalho, eles iam olhar a cozinha e olhavam até dentro do lixo, pra ver se eu tinha escondido, assim, se eu me machuquei, não sei o que (PVHA mulher UD 6).

$\mathrm{Na}$ forma direta, os entrevistados da unidade de saúde relataram que a discriminação acontece quando o diagnóstico é revelado. No emprego formal, a aids pode ser um pretexto para retirar da empresa um empregado indesejado, sendo que a condição sorológica pode ser utilizada como um facilitador para a demissão. Entre aqueles com emprego informal, o medo da "contaminação" afasta as pessoas do convívio dos soropositivos, ressaltando a discriminação:

Olha só, veja bem, a senhora, nós que vivemos, nós que vivemos o problema, nós sabemos o que é discriminação, preconceito, tem pessoas que não pegam nem na minha mão, tem pessoas que saem de perto de mim, sabe, eu sofro todo dia com isso. Eu escuto as pessoas, que eu trabalho no Camelódromo ali, ajudando os camelôs lá, eu vejo pessoas, eu já escutei várias vezes, ó, cuidado que ele tem aids (PVHA homem UD 3).

Houve também depoimentos das PVHA ligadas à ONG sobre a discriminação no trabalho, de forma direta e indireta. Contudo, os relatos foram mais detalhados no que tange à discriminação no trabalho e que culminaram em processos.

Na discriminação indireta, houve o impedimento de progressão na carreira de um piloto da aviação doméstica e uma entrevistada foi isolada, na agência de viagens onde trabalhava, após revelar a sorologia positiva para o HIV através de um e-mail para os diretores, gerando diversas situações para forçá-la a pedir demissão (sem produzir provas para um possível processo):

\footnotetext{
Não, teve mais gente que ficou sabendo e a minha profissão é o seguinte, minha profissão você tem turmas, são grupos, então quando você entrar, você tem a sua turma, são 10 pessoas, 15 pessoas, é antiguidade, então quando chega na época da sua turma ser promovida, é a sua turma que vai ser promovida [...] então até preterido pra promoção eu fui por causa desse problema (PVHA Homem ONG 1).

Daí então eu comecei a notar que eles começaram a me pressionar de várias formas possíveis, mandando eu fazer coisas que não eram da minha função, ligando pra minha casa tarde da noite [...] Fizeram uma série de coisas [...] eles já estavam criando uma
} 
situação pra me mandar embora, provocando uma série de situações pra que eu pedisse a demissão, né, e, quer dizer, me jogando ali de escanteio (PVHA Mulher ONG 2).

Contudo, houve casos de discriminação direta e indireta relacionado a um militar da Aeronáutica. No que tange à forma direta, a discriminação ocorreu quando o diagnóstico foi revelado para os seus superiores da Aeronáutica. A partir disso, outros soldados começaram a discriminar o entrevistado, utilizando a palavra "aidético": "[...] desde o momento que eu faço a barba e se sangra e eu pego aquilo ali pra lavar na pia, aí tem murmurinho de dizer, vamos lavar porque o 'aidético' acabou de sangrar a pia toda aí” (PVHA Homem ONG 3). Outro exemplo de discriminação relatado por ele foi a dispensa da educação física, principalmente pelo medo dos superiores de que ele infectasse outras pessoas, em caso de acidente.

Como consequência de diversas discriminações passadas na Aeronáutica, o entrevistado resolveu lutar pela sua reforma militar, ou seja, aposentadoria. Além da discriminação sofrida no ambiente de trabalho, outro ponto que pesou em sua decisão foi a impossibilidade de subir de patente, pois o estatuto das Forças Armadas impede a progressão na carreira militar em função do teste compulsório de HIV.

Os entrevistados da unidade de saúde chamaram a atenção para a dificuldade da reinserção no mercado de trabalho. Entre os relatos, há aqueles que trabalham informalmente e outros que, após perderem o emprego, acreditam que, por terem HIV/aids, foram recusados em diversos processos seletivos, sobretudo pelo exame de sangue realizado na admissão (mesmo proibido por lei).

Dessa forma, a questão do exame de sangue admissional no processo seletivo foi enfatizada no grupo focal na unidade de saúde. Para os entrevistados, as empresas realizam o exame de HIV e esse pensamento está ligado, sobretudo, à falta de contato com os candidatos após a realização do exame de sangue, ou mesmo quando as empresas pedem para que os candidatos refaçam os testes no posto de saúde. Com isso, eles acreditam que essa ausência de comunicação está relacionada com a descoberta do HIV após a realização dos exames admissionais: “[...] eu senti que na hora que eu passei nas provas e tudo, quando chegou no exame de sangue que eles falaram pra mim que eu tinha que voltar [...] eles mandaram eu retornar no posto do Sistema Único de Saúde (SUS) pra fazer o exame” (PVHA mulher UD 4).

Já outro entrevistado (PVHA homem UD 5) argumentou que não consegue a reinserção no mercado de trabalho porque as empresas podem consultar os seus dados, através do CPF, no Instituto Nacional do Seguro Social (INSS) e, dessa forma, investigar o motivo pelo qual retirou o Fundo de Garantia (FGTS). Entretanto, essa informação foi esclarecida por um ativista da 
ONG, argumentando que só é permitido às empresas consultar se o candidato já retirou o FGTS, mas sem saber o motivo.

Outra forma de discriminação apontada pelas PVHA, tanto da unidade de saúde quanto da ONG, foi em relação aos colegas de trabalho. Quase todos os entrevistados guardaram segredo sobre o diagnóstico no ambiente de trabalho. Um dos entrevistados informou que seus colegas insinuavam que a transmissão do vírus poderia ocorrer somente por trabalhar com uma pessoa HIV positiva: "Chegaram a usar, um deles chegou a usar que na minha equipe, nos meus pilotos, não vai ter ninguém, não pode ter ninguém infectado, não pode ter ninguém 'costa quente’ [...] aqui a gente não aceita” (PVHA Homem ONG 1).

O medo revelar a infecção do HIV em função dos preconceitos existentes na sociedade brasileira aparece no relato de uma entrevistada. Ela não foi bem acolhida ao contar para os filhos sobre a sua sorologia e imagina que essa discriminação pode surgir, principalmente, em empregos com contato direto com o público, como o dela: "As pessoas fingem que não tem preconceito, elas querem ser politicamente corretas o tempo todo" (PVHA Mulher ONG 2).

O entrevistado da Aeronáutica lembrou que é uma pessoa com acesso à informação e ligado ao movimento social de aids e, mesmo assim, passa por diversos constrangimentos, o que leva o entrevistado a pensar naqueles que não possuem nenhum apoio ou conhecimento sobre os seus direitos.

\section{DISCUSSÃO}

A partir dos depoimentos das PVHA entrevistadas, é possível entender que a discriminação dessa população no ambiente de trabalho ainda é uma realidade no Brasil. A literatura internacional converge com os dados da pesquisa, como observado no depoimento de uma entrevistada da unidade de saúde que já trabalhou como cozinheira. No seu depoimento ela indica que o lixo do restaurante era revirado para verificar se ela tinha se cortado com a faca (PVHA mulher UD 6). Nos artigos europeus, há relatos de acusações de contágio do HIV para a "terceira pessoa", como em Portugal (PEREIRA, 2010). Nos julgamentos, há uma clara falta de conhecimento científico por parte dos juízes, pois indicam o perigo da transmissão do vírus através do sangue, das lágrimas e do suor, no momento do preparo dos alimentos. O desconhecimento das formas de transmissão do HIV também se aplica aos empregadores e, por isso, foram criados diversos tratados internacionais, além dos documentos da Organização Internacional do Trabalho (OIT), para regulamentar os deveres dos empregadores que contratam as PVHA (PEREIRA, 2010; SALCEDO; TOVAR; ARRIVILLAGA, 2013). 
Apesar dos entrevistados da pesquisa sofrerem discriminação, ninguém pediu demissão para que o diagnóstico não fosse revelado. Este dado se distingue da literatura nacional sobre o tema, que aponta a demissão como uma ferramenta de proteção pelas PVHA, principalmente entre os homens (GARRIDO et al., 2007). Algumas PVHA entrevistadas na pesquisa declararam abertamente para os seus empregadores que estavam infectadas pelo HIV e tiveram como resultado a demissão ou sofreram algum tipo de pressão para pedirem demissão. $O$ fato foi observado, principalmente, entre os entrevistados da ONG. Foi a partir da revelação do diagnóstico que os atos discriminatórios começaram a acontecer nos locais de trabalho. Como exemplo, pode-se mencionar uma entrevistada da ONG (PVHA Mulher ONG 2) que, após passar um e-mail para os diretores da empresa onde trabalhava contando sobre a sua sorologia, ela foi isolada em uma sala, outra funcionária começou a aprender o seu trabalho para substituíla, além de realizar funções que não desempenhava antes.

Há distinções sobre a percepção de discriminação no emprego entre homens e mulheres vivendo com HIV/aids. Para os homens, o trabalho é visto como um obstáculo relacionado ao bem-estar, afetando a identidade masculina e acarretando em diversos problemas de saúde. A aposentadoria por invalidez é uma saída para aqueles que não conseguem emprego, mas pode ser considerado como um "atestado de exclusão" por eles. Além disso, o recebimento do auxílio doença pode influenciar na dificuldade de reinserção no mercado de trabalho (GARRIDO et al., 2007). Em relação as mulheres, o medo é vivenciado pela possibilidade de demissão em função da revelação do diagnóstico. Contudo, para elas, o trabalho compõe a renda familiar, significando a independência econômica e sendo utilizado também para afastar o pensamento recorrente sobre a doença. A dificuldade na manutenção do emprego está em adequar os horários de trabalho com as consultas médicas (CECHIM; SELLI, 2007; FERREIRA; FIGUEIREDO; SOUZA, 2011).

A pesquisa quantitativa indicou quase $60 \%$ dos entrevistados não estavam trabalhando no momento da entrevista e aproximadamente $21 \%$ perderam o emprego após o diagnóstico do HIV. A hipótese é que a demissão possa estar vinculada à revelação do diagnóstico para o empregador ou que a piora da saúde possa ter influenciado a sua dispensa. A perda do emprego ocasionou a piora da situação financeira, a mudança de local de moradia e a perda de independência para as PVHA. A literatura nacional indica que o ambiente de trabalho pode propiciar a melhora da qualidade de vida das PVHA, principalmente nos aspectos psicológicos e nas relações sociais, indo além dos benefícios dos antirretrovirais (CASTANHA et al., 2007). O trabalho também pode proporcionar a essa população uma reinserção social, afetando 
positivamente a autoestima e causando "bem-estar, respeito próprio, dignidade" e cidadania (FREITAS et al., 2012).

A discriminação na estrutura das empresas e/ou instituições públicas, chamada de violência estrutural (GALTUNG, 2004), também ficou evidente no serviço militar, como relatado pelo entrevistado que trabalhava na Aeronáutica (PVHA Homem ONG 3). As Forças Armadas têm regras rígidas para os militares no que se refere à licença médica, ou até mesmo para aqueles que querem se aposentar (reforma militar) e que já fazem parte do quadro do serviço. Mesmo passando pela Perícia Médica da Aeronáutica (CEMAL) e levando os laudos da infectologista, o entrevistado não obteve a licença do trabalho.

Além disso, o teste de HIV é de caráter compulsório para o ingresso nas Forças Armadas a partir da patente de sargento, sendo considerado por muitos de caráter discriminatório. A realização do teste é amparada pela Portaria Normativa No 1174, do Ministério da Defesa, de 6 de setembro de 2006, que aprova as normas para avaliação das incapacidades decorrentes de doenças especificadas em lei pelas Juntas de Inspeção de Saúde das Forças Armadas.

Por meio do conceito de Goffman (2013), pode-se dizer que as PVHA que são identificadas dentro desse contexto de trabalho não são aceitas socialmente e são consideradas inaptas para o serviço militar, recebendo uma "marca" que as identifica. A consequência são os atos discriminatórios, sendo uma resposta comportamental e praticada com atitudes negativas, efetivando o preconceito e o estigma dentro desse espaço (PARKER, 2013).

Outro caso relacionado à $\mathrm{ONG}$ se refere ao piloto da aviação civil que sofreu discriminação a partir do momento em que a empresa soube do seu diagnóstico positivo para o HIV (PVHA Homem ONG 1). Apesar de ter o apoio do médico do trabalho, um dos diretores da companhia aérea impediu a sua permanência na empresa e seu posto foi mantido por uma liminar judicial. Desde a exposição do seu diagnóstico, ele começou a sofrer a discriminação direta, relacionada aos seus colegas de trabalho, e indireta, vinculada a um dos diretores da empresa, que queria afastar o entrevistado de qualquer forma. Além disso, apreenderam a sua carteira de saúde, sem a qual não poderia voar.

Partindo desses relatos, entende-se que a discriminação pode refletir negativamente na vida das PVHA, ocorrendo de forma direta e indireta (GALTUNG, 2004). No caso de uma entrevistada da ONG, a discriminação direta foi percebida, principalmente, por meio da reação inesperada dos filhos, quando contou sobre o seu diagnóstico. Além disso, ela tinha receio que seus clientes descobrissem a sua soropositividade, pois trabalhava em uma agência de viagens e lidava diretamente com o público. Assim, a desinformação sobre a transmissão do vírus e a falta de políticas em torno dos aspectos sociais da aids tem contribuído para o receio dessa 
população em revelar o diagnóstico para a família, amigos e parceiros sexuais (PEREIRA; MONTEIRO, 2015). Herbert Daniel, militante da sociedade civil de aids e fundador do Grupo Pela Vidda Rio, já dizia, na década de 1980, que o combate ao vírus ideológico era muito mais difícil do que o enfrentamento do vírus biológico (GROTZ; PARKER, 2015) e classificava de "morte civil" a exclusão social pela qual as PVHA passavam no começo da epidemia.

Diversos autores indicam que a falta de informação está na raiz dos comportamentos discriminatórios e a mudança de atitude só seria possível com programas de intervenção, sobretudo para os empregadores e aqueles responsáveis pelas contratações, reduzindo o estigma relacionado às PVHA (SURGEVIL; AKYOL, 2011; LIU, 2012). Contudo, a mudança de visão só seria possível por meio de uma abordagem em que essas atitudes e crenças preconceituosas pudessem ser debatidas, para que acontecessem as transformações estruturais necessárias e, com isso, o mercado de trabalho se abrisse para as PVHA (LINK; PHELAN, 2001).

Os dados quantitativos e qualitativos também apontam a dificuldade da reinserção dessa população no mercado de trabalho, sobretudo na hora da contratação e no exame admissional, apontado como uma barreira nas empresas em função da coleta de sangue. Isso se repete em todas as oportunidades de emprego para aqueles excluídos nessa etapa. A saída, para muitos, é conseguir uma ocupação informal, que pode não garantir uma remuneração fixa mensal. A testagem do HIV para o acesso ao trabalho é proibida por lei, como indicado na Portaria $\mathrm{N}^{\circ}$ 1.246/2010 do Ministério do Trabalho; contudo, não há o controle dos exames admissionais no Brasil e, por isso, muitas empresas realizam o teste sem o conhecimento do candidato.

Além da quebra do sigilo no exame de sangue admissional, há outros fatores que podem influenciar negativamente a entrada das PVHA no mercado de trabalho. Como exemplo, a pergunta se o candidato possui alguma doença grave nas fichas de seleção, além dos sucessivos pedidos de auxílio-doença ao INSS, pois as empresas podem ficar desconfiadas que determinado candidato tem algum problema sério de saúde (GARRIDO et al., 2007). Phelan et al. (2013), correlacionaram os processos estigmatizantes aos comportamentos, sendo classificados por eles como uma "discriminação estrutural" e concretizada a partir das atitudes preconceituosas. Um exemplo é a discriminação no processo seletivo nas empresas e relatado pelos entrevistados da unidade de saúde.

A análise dos dados sociodemográficos da pesquisa quantitativa apontou que a idade e a escolaridade foram fatores que influenciaram na inserção ou não dos entrevistados no mercado de trabalho. Quanto mais baixa a escolaridade e mais velho o entrevistado, menores as chances de emprego, sobretudo entre aqueles na faixa etária da população economicamente ativa. Alguns autores correlacionam determinados fatores que dificultam o acesso ao trabalho 
para as PVHA, como, por exemplo, baixa escolaridade, pouca qualificação e experiência profissional (DRAY-SPIRA et al., 2003). Isso indica que o desemprego pode ter graves consequências para as PVHA no Brasil, afetando o autocuidado dessa população e, consequentemente, reduzindo as chances de emprego. No entanto, entre aqueles com ensino superior, uma parcela considerável, sobretudo as mulheres (50\%), não estava trabalhando no momento da entrevista, assinalando a possibilidade de outros fatores para a não permanência das PVHA no trabalho, como o estado de saúde.

Já em relação aos obstáculos para a permanência no emprego, os entrevistados indicaram que a discriminação entre os colegas de trabalho (discriminação direta) é um fator que contribui para que as PVHA decidam sair das empresas, como também um motivador para que lutem por suas aposentadorias. Além disso, o medo da discriminação faz com que as PVHA não revelem o diagnóstico no ambiente de trabalho. Para isso, muitos utilizam diversas estratégias para que o HIV fique em segredo, como no pedido de declaração para as assistentes sociais ao invés de levarem o atestado médico carimbado por um infectologista, ou mesmo quando não conseguem explicar as diversas ausências em função das consultas médicas.

Por outro lado, a discriminação indireta, classificada por Galtung (2004), de invisível e onde está inserida a violência estrutural, revela-se tanto no poder desigual como nas oportunidades de vida desiguais (GALTUNG,1969; PARKER, 2013; HO, 2007). Dessa forma, a estigmatização foi vinculada aos processos sociais de forma mais ampla, ou seja, não necessariamente a discriminação ocorre com um indivíduo, mas a partir de uma estrutura que facilite que ela aconteça (PARKER, AGGLETON, 2003). Esse tipo de violência também revela como o poder é exercido de forma desigual entre os empregadores e os empregados e está associado, sobretudo, a sua distribuição entre os atores sociais (GALTUNG, 1969; PARKER, 2013; HO, 2007).

A entrevistada que trabalhava em uma agência de viagens, após passar por muita pressão para que pedisse demissão, conseguiu ficar por dois anos de licença médica. Ela desenvolveu a síndrome do pânico ${ }^{3}$, relacionada ao trabalho e, por isso, tem "pavor" de voltar para o emprego. Ela indica que a discriminação indireta foi realizada de forma sutil, para que não fossem geradas provas em um futuro processo (PVHA Mulher ONG 2). A revelação do diagnóstico para os empregadores também afetou uma entrevistada da unidade de saúde (PVHA mulher UD 1). Ela contou que estava com HIV para o seu chefe e o filho dele começou a pressionar o pai para

\footnotetext{
${ }^{3}$ Segundo Salum et al. (2009, p. 86): "O transtorno do pânico (TP) é caracterizado pela presença de ataques de pânico recorrentes, que consistem em uma sensação de medo ou mal-estar intenso, acompanhada de sintomas físicos e cognitivos e que se iniciam de forma brusca, alcançando intensidade máxima em até 10 minutos".
} 
demiti-la. Neste caso, o diagnóstico positivo para o HIV foi utilizado como um pretexto para que o filho do dono da empresa pudesse retirá-la do cargo de secretária.

Outra possibilidade de as empresas descobrirem o diagnóstico de HIV/aids dos seus empregados é pelo CID (Classificação Internacional de Doenças), no pedido de auxílio-doença do INSS, onde a aids é classificada de B20 até B24. Contudo, segundo a Resolução do Conselho Federal de Medicina $\mathrm{N}^{\circ} 1.658$, de 20 de dezembro de 2002, Art. $5^{\circ}$, que regulamenta a emissão dos atestados: "Os médicos somente podem fornecer atestados com o diagnóstico codificado ou não quando por justa causa, exercício de dever legal, solicitação do próprio paciente ou de seu representante legal". O adoecimento seria uma forma de prejudicar o lucro das empresas e, por isso, aqueles com doenças crônicas e estigmatizantes, como a aids, estariam atrelados a uma condição negativa tanto para a permanência quanto na contratação do emprego (LAURELL, 1982). A permanência das PVHA no emprego também é permeada por outros fatores, como a capacidade física e psicológica para se manterem nos postos de trabalho.

A perda da renda também afetou os entrevistados da unidade de saúde. Uma PVHA que trabalhava como cuidadora de crianças teve que se afastar dessa função porque uma das mães descobriu o seu diagnóstico e ficou com medo dela transmitir o HIV para a filha, como, por exemplo, por arranhões (PVHA mulher UD 6). Em outro caso, um entrevistado que trabalhava como camelô disse como sofria com o preconceito diariamente. Ele tem que se controlar todos os dias para não brigar com outras pessoas em função da discriminação direta (PVHA homem UD 3). Assim, a falta de informação sobre as formas de transmissão do vírus ainda é latente no Brasil. A discriminação direta pode gerar uma perda financeira para essa população, sobretudo pela produção das hierarquias sociais e na classificação das PVHA em categorias distintas, em função da construção de estereótipos (LINK; PHELAN, 2001).

Em relação à capacidade física de as PVHA se manterem no trabalho, uma hipótese é que aqueles com um longo tempo de exposição ao vírus e ao uso da TARV têm uma maior probabilidade de desenvolver sequelas e comorbidades, podendo trazer alguma incapacidade física para as PVHA. Entre os entrevistados soropositivos, há relatos de como o HIV/aids e o uso dos medicamentos influenciaram na não permanência no emprego. Uma entrevistada da unidade de saúde falou como se sentia cansada e, por isso, pediu para que o seu empregador a demitisse (PVHA mulher UD 6). Outro entrevistado, que trabalha na Aeronáutica, relatou como a baixa imunidade afetou o seu desempenho nas atividades do trabalho e, por isso, batalhou para que fosse transferido para a área administrativa do quartel (PVHA Homem ONG 3).

Um artigo elaborado a partir dos dados quantitativos analisados nessa pesquisa apontou que a boa autoavaliação de saúde das PVHA é percebida por meio da ausência de sintomas 
relacionados ao HIV, como a falta dos efeitos colaterais dos medicamentos, mas a baixa contagem de $\mathrm{CD}^{+}{ }^{+}$piora a percepção sobre a saúde. Além disso, muitas PVHA entrevistadas não superaram os traumas psicológicos gerados pela descoberta do diagnóstico, sendo um aspecto importante na autoavaliação da saúde (SOUZA-JÚNIOR; SZWARCWALD; CASTILHO, 2011). A percepção da qualidade de vida dessa população também é permeada por outros fatores, tais como: idade; escolaridade; sexo; estado civil; renda mensal; nível de linfócitos $\mathrm{CD}^{+}{ }^{+}$e outros (FERREIRA; OLIVEIRA; PANIAGO, 2012).

O apoio e a inclusão social são outros fatores para a boa qualidade de vida das PVHA, sobretudo de família e amigos, sendo importante para a motivação pela busca do emprego, além da boa relação médico-paciente para a manutenção das PVHA no tratamento, ajudando na melhora da saúde desses indivíduos (OLIVEIRA FILHO et al., 2014; PEREIRA; SILVA; OLIVEIRA, 2015). Com a inclusão social, o medo do estigma e a discriminação podem não se tornar central na vida dessa população, afetando positivamente a condição psicológica das PVHA. Há autores que chamam atenção para o trabalho que deve ser realizado entre indivíduos, conjugado com fatores institucionais, sociais e em parceria com as famílias para que as PVHA possam ter aderência à TARV para uma melhor qualidade de vida. Além disso, os serviços de saúde podem realizar intervenções em torno dos aspectos culturais e estruturais dos soropositivos. A participação da comunidade, sobretudo no aprendizado em como lidar com o estigma da aids pode fazer parte das estratégias na superação de obstáculos, na promoção dos direitos humanos e nas mudanças, tanto da legislação quanto das práticas discriminatórias contra essa população (CRUZ et al., 2015).

Para aqueles com dificuldade em se manter no emprego por conta de problemas de saúde relacionados a HIV/aids, principalmente após um longo período de tratamento, cabe ressaltar a importância da Perícia Médica do INSS, para que as PVHA possam conseguir o auxílio-doença no período que estiverem debilitadas para o trabalho, assim como a aposentadoria para aqueles que ficaram incapacitados. O problema é que a perícia, tanto do INSS quanto do CEMAL (Aeronáutica), tem como foco a avaliação dos aspectos físicos dos soropositivos.

Mesmo com a implementação da Resolução No 416 do INSS, de 2014, que amplia a avaliação da perícia médica para HIV/aids, Hanseníase e Tuberculose, incluindo as complicações psicológicas e o impacto do estigma e da discriminação na vida das PVHA, para os entrevistados, essa resolução não é utilizada no momento da avaliação. A perícia ainda continua ignorando os aspectos sociais de HIV/aids, onde a falta de igualdade de oportunidades de emprego é uma realidade. Outro problema relacionado à perícia é quando os médicos não 
observam as particularidades de cada PVHA, avaliando todas da mesma forma por meio dos exames laboratoriais, como $\mathrm{CD}^{+}$, carga viral e outros. A própria resolução deixa claro que cada PVHA tem que ser avaliada de forma individual, o que não acontece de fato.

Desse modo, ter acesso aos benefícios do INSS está a cada dia mais difícil para as PVHA, em função de como é feita a perícia médica. Uma entrevistada da ONG relatou que o perito só autorizou o auxílio-doença em função das cirurgias que ela tinha realizado (PVHA Mulher ONG 2). Por dois anos, de três em três meses, ela foi avaliada pelo mesmo perito e que deixou claro que a síndrome do pânico não seria um motivador para a entrevistada receber o benefício. Já outro entrevistado da ONG teve a quebra do sigilo do diagnóstico, quando passou pela perícia do CEMAL, não conseguindo o afastamento do trabalho porque, para os médicos, ele não apresentava as características das pessoas adoecidas pela aids (PVHA Homem ONG 3).

Entre aqueles que tiveram acesso aos benefícios da Lei Orgânica da Assistência Social (LOAS), 35\% perderam o emprego entre os homens e 38,5\% entre as mulheres. Grande parte daqueles que perderam o emprego não tinham instrução ou apenas o ensino fundamental incompleto $(27,6 \%)$ ou o ensino fundamental completo e médio incompleto (24\%). Assim, os resultados indicaram que o pedido de benefícios está diretamente relacionado com a baixa escolaridade e, consequentemente, renda.

O estigma e a discriminação se articulam com diversos marcadores sociais e que apareceram no decorrer das entrevistas, tais como: classe; gênero; sexualidade; renda; escolaridade; idade; entre outros. A grande maioria das PVHA exerciam funções em que eram subordinadas a uma pessoa, seja formalmente ou informalmente, onde o estigma e a discriminação emergiram (cozinheira, camelô, cuidadora de crianças etc.). Por exemplo, o militar era um soldado homossexual e que estava em um ambiente masculino e seu superior direto tinha HIV, mas ninguém sabia. Já a sua sorologia foi divulgada para diversas pessoas dentro do quartel. Dessa forma, a interseccionalidade (interseções de diversos fenômenos) é um elemento que converge no estigma e na discriminação das PVHA no que tange as distintas categorias que atravessam a sua análise (MONTEIRO; VILLELA; SOARES, 2013).

\section{CONSIDERAÇÕES FINAIS}

O presente estudo teve o propósito de compreender a discriminação no trabalho, entre as PVHA, a partir de dados quantitativos, de âmbito nacional, e qualitativos, por meio de trabalho de campo e depoimentos de PVHA que acessaram uma Policlínica no município do Rio de Janeiro ou Assessoria Jurídica de uma ONG. 
Ainda que com uma defasagem de onze anos em relação aos dados quantitativos, coletados em 2008, foram observados elementos semelhantes na pesquisa qualitativa, sendo que a discriminação foi mais percebida entre os indivíduos com baixo poder econômico e que buscaram benefícios do governo, principalmente pela falta de preparo para o disputado mercado de trabalho. Neste sentido, a análise qualitativa veio a complementar os resultados da análise quantitativa, refletindo os processos experimentados pelas PVHA nas respostas obtidas no inquérito de 2008.

$\mathrm{O}$ estigma relacionado a HIV/aids na pesquisa se articulou com outros preexistentes na sociedade, como aqueles vinculados à homofobia, à classe social, a gênero, entre outros. Dessa forma, observa-se a necessidade de ser criar programas de intervenção no Brasil, sobretudo cultural, para a conscientização dos diversos aspectos da epidemia e que levem em consideração o estigma e a discriminação das PVHA articulados a esses outros marcadores sociais.

Os efeitos visíveis e invisíveis da discriminação no emprego fazem parte do panorama dessa realidade para as PVHA no país e é a partir do enfrentamento da discriminação no trabalho, da abertura dos processos, do acesso às informações sobre os direitos, da implementação de programas de intervenção e do fortalecimento da sociedade civil de aids que ocorre o empoderamento dessa população (PEREIRA, 2017). 


\section{REFERENCIAS}

BASTOS. F. I. Aids na Terceira Década. Rio de Janeiro: Editora Fiocruz, 2006.

BASTOS. F. I. Da Persistência das Metáforas: estigma e discriminação \& HIV/Aids. In: MONTEIRO, S.; VILLELA, W. (orgs.). Estigma e Saúde. Rio de Janeiro: Editora Fiocruz, 2013, p. 91-103.

BEZABHE, W. M. et al. Barriers and Facilitators of Adherence to Antiretroviral Drug Therapy and Retention in Care among Adult HIV-Positive Patients: a Qualitative Study from Ethiopia. PLoS One, San Francisco, v. 9, n. 5, e97353, 2014.

BOLETIM EPIDEMIOLÓGICO: HIV AIDS. Brasília: Ministério da Saúde, julho de 2017 a junho de 2018. ISSN: 1517-1159. Disponível em: http://www.aids.gov.br/ptbr/pub/2018/boletim-epidemiologico-hivaids-2018. Acesso em: 29 nov. 2018.

CASTANHA, A. R. et al. Avaliação da qualidade de vida em soropositivos para o HIV. Estudos de Psicologia, Campinas, v. 24, n. 1, p. 23-31, jan./mar. 2007.

CECHIM, P. L.; SELLI, L. Mulheres com HIV/AIDS: fragmentos de sua face oculta. Rev. Brasileira de Enfermagem, Brasília, v. 60, n. 2, p. 145-9, mar./abr. 2007.

CONSELHO FEDERAL DE MEDICINA. Resolução n. ${ }^{\circ}$ 1.658/2002, de 20 de dezembro de 2002. Normatiza a emissão de atestados médicos e dá outras providências. Disponível em: http://www.portalmedico.org.br/resolucoes/CFM/2002/1658_2002.htm. Acesso em: 16 fev. 2017.

CRUZ, M. L. S. et al. The "moral career" of perinatally HIV-infected children: revisiting Goffman's concept. AIDS Care, Abingdon, v. 27, n. 1, p; 6-9, 2015.

DRAY-SPIRA, R. et al. Socio-economic conditions, health status and employment among persons living with HIV/AIDS in France in 2001. AIDS Care, Abingdon, v. 15, n. 6, p. 739$748,2003$.

FERREIRA, R. C. M.; FIGUEIREDO, M. A. de C. SOUZA, L. B. Trabalho, HIV/AIDS: enfrentamento e dificuldades relatadas por mulheres. Psicologia em Estudo, Maringá, v. 16, n. 2, p. 259-267, abr./jun. 2011.

FERREIRA, B. E.; OLIVEIRA, I. M.; PANIAGO, A. M. M. Qualidade de vida de portadores de HIV/AIDS e sua relação com linfócitos CD4+, carga viral e tempo de diagnóstico. Rev Bras Epidemiol, São Paulo, v. 15, n. 1, p. 75-84, 2012.

FORATTINI, O. P. AIDS e Sua Origem. Revista de Saúde Pública, São Paulo, v. 27, n. 3. Editorial, p. 153-156, 1993.

FREITAS, J. G. et al. Enfrentamentos experienciados por homens que vivem com HIV/Aids no ambiente de trabalho. Rev Esc Enferm USP, São Paulo, v. 46, n. 3, p. 720-6, 2012.

GALTUNG, J. Violence, Peace, and Peace Research. Journal of Peace Research, London, v. 6, n. 3, p. 167-191, 1969. 
GALTUNG, J. Violencia, guerra y su impacto. Sobre los efectos visibles e invisibles de la violência. Polylog: Foro para filosofía intercultural, Amberg, n. 5, 2004. Disponível em: https://them.polylog.org/5/fgj-es.htm. Acesso em: 08 jun 2015.

GARRIDO, P. B. et al. Aids, estigma e desemprego: implicações para os serviços de saúde. Revista de Saúde Pública, São Paulo, v. 41, supl. 2, p. 72-9, dez. 2007.

GOFFMAN, E. Estigma: Notas sobre a manipulação da identidade deteriorada. Rio de Janeiro: LTC, 2013.

GROTZ, F.; PARKER, R. O retorno do vírus ideológico. Boletim ABIA, Rio de Janeiro, n. 60, p. 19-21, jun. 2015.

INSTITUTO NACIONAL DO SEGURO SOCIAL. Resolução nº 416/PRES/INSS, de 4 de junho de 2014. Aprova Diretrizes de Apoio à Decisão Médico-Pericial em Clínica Médica Volume III - Parte II do Manual de Procedimentos em Benefícios por Incapacidade. Dispõem sobre as doenças infectocontagiosas, especificamente HIV/AIDS, Tuberculose e Hanseníase. Diário Oficial da União: seção 1, Brasília, DF, 2014, n. 106, p. 35, 5 junho 2014.

HO, K. Structural Violence as a Human Rights Violation. Essex Human Rights Review, Colchester, v. 4, n. 2, p. 1-17, sept. 2007.

LAURELL, A. C. La salud-enfermedad como proceso social. Revista Latinoamericana de Salud, México, v. 2, p. 7-25, 1982.

LINK, B.; PHELAN, J. Conceptualizing Stigma. Annual Review of Sociology, Palo Alto, v. 27, p. 363-85, 2001.

LIU, Y. et al. HIV-related stigma acting as predictors of unemployment of people living with HIV/AIDS. AIDS Care, Abingdon, v. 24, n. 1, p. 129-135, 2012.

MINAYO, M. C. S. O desafio do conhecimento: pesquisa qualitativa em saúde. São Paulo: Hucitec, 2014.

MONTEIRO, S. S.; VILLELA, W. V.; SOARES, P. S. The interaction between axes of inequality in studies on discrimination, stigma and HIV/AIDS: Contributions to the recent international literature. Global Public Health, London, v. 8, p. 519-533, 2013.

OLIVEIRA FILHO, J. S. et al. Qualidade de vida de pessoas vivendo com HIV/AIDS. Revista Baiana de Enfermagem, Salvador, v. 28, n. 1, p. 61-68, jan./abr. 2014.

PARKER, R. Interseções entre Estigma, Preconceito e Discriminação na Saúde Pública. In: MONTEIRO, S.; VILLELA, W. (orgs.). Estigma e Saúde. Rio de Janeiro: Editora Fiocruz, 2013, p. 25-46.

PARKER, R.; AGGLETON, P. HIV and Aids related stigma and discrimination: a conceptual framework and implications for action. Social Science \& Medicine, Oxford, v. 57, p. 13-24, 2003. 
PEREIRA, A. News and views: HIV/Aids and discrimination in the workplace: The cook and the surgeon living with HIV. European Journal of Health Law, Boston, v. 17, n. 2, p. 139$147,2010$.

PEREIRA, C. R.; MONTEIRO, S. S. A criminalização da transmissão do HIV no Brasil: avanços, retrocessos e lacunas. Physis Revista de Saúde Coletiva, Rio de Janeiro, v. 25, n. 4, p. 1185-1205, 2015.

PEREIRA, C. R.; MONTEIRO, S. S. A violação dos direitos das pessoas vivendo com HIV/aids no Brasil: Análise da discriminação no universo do trabalho. Tese (Doutorado) Programa de Pós-Graduação em Comunicação e Saúde, Fundação Oswaldo Cruz, 2017.

PEREIRA, D. M. A.; SILVA, M. G. A. C.; OLIVEIRA, D. C. Qualidade de vida de indivíduos com HIV. Revista Saúde em foco, Teresina, v. 2, n. 1, art. 7, p. 93-112, jan./jul. 2015.

PITTS, M. K.; GRIERSON, J.; MISSON, S. Growing older with HIV: a study of health, social and economic circumstances for people Living with HIV in Australia over the age of 50 years. AIDS Patient Care and STDs, New York, v. 19, n. 7, p. 460-465, 2005.

PHELAN, J.; LINK, B.; DOVIDIO, J. Estigma e Preconceito: um animal ou dois? In: MONTEIRO, S.; VILLELA, W. (orgs.). Estigma e Saúde. Rio de Janeiro: Editora Fiocruz, 2013, p. 183-2070.

SAlCEDO, J. P., TOVAR, L. M.; ARRIVIllaGA, M. Aportes de la Organización Internacional del Trabajo al mundo laboral de las personas con VIH/sida. Revista Cubana de Salud Pública, Havana, v. 39, n. 4, p.708-717, 2013.

SALUM, G. A.; BLAYA; C.; MANFRO; G. G. Transtorno do pânico. Revista de Psiquiatria, Rio Grande do Sul, v. 31, n. 2, p. 86-94, 2009.

SOUZA-JÚNIOR, P. R. B. Percepção da Qualidade de Vida e do Desempenho do Sistema de Saúde entre Pacientes em Terapia Anti-Retroviral no Brasil. Tese (Doutorado) - Escola Nacional de Saúde Pública, Fundação Oswaldo Cruz, 2009.

SOUZA-JÚNIOR, P. R. B.; SZWARCWALD, C. L.; CASTILHO, E. A. Self-rated health by HIV-infected individuals undergoing antiretroviral therapy in Brazil. Cadernos de Saúde Pública, Rio de Janeiro, v. 27, p. s56-s66, 2011.

SURGEVIL, O.; AKYOL, E. M. Discrimination against people living with HIV/AIDS in the workplace: Turkey context. Equality, Diversity and Inclusion, v. 30, n. 6, p. 463-481, 2011.

SZWARCWALD, C. L.; BASTOS, F. I.; CASTILHO, E. A. The Dynamics of the Aids Epidemic in Brazil: A Space-Time Analysis in the Period 1987-1995. The Brazilian Journal of Infectious Diseases, São Paulo, v. 2, n. 4, p. 175-186, 1998. 